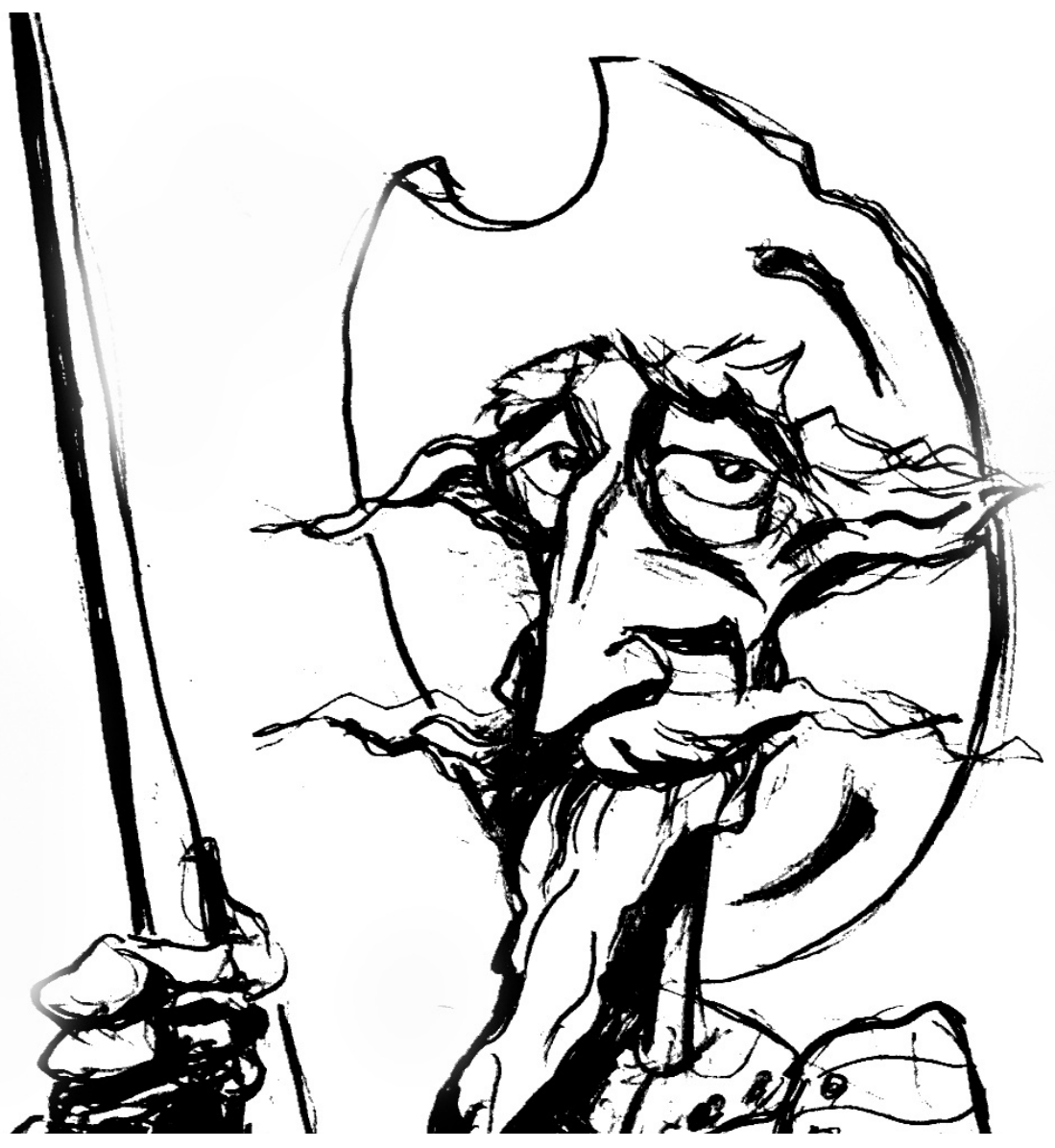

Los embajadores del Consell de Cent en la corte de España. Aproximación a la actividad diplomática de la ciudad de Barcelona en la época moderna

[Mathias Ledroit] 



\title{
Los embajadores del Consell de Cent en la corte de España. Aproximación a la actividad diplomática de la ciudad de Barcelona en la época moderna*
}

\author{
The Ambassadors of the Consell de Cent at the Spanish Cort. An Approach to \\ the Diplomatic Activity of the City of Barcelona in Premodern Times
}

MATHIAS LEDROIT

\section{Resumen}

Las legaciones de la ciudad de Barcelona a la Corte de España en Madrid son un mecanismo institucional conocido para los historiadores de la época moderna que, sin embargo, no se ha beneficiado de ningún estudio. En el presente artículo, se tratará de exponer los primeros resultados de una investigación sobre la práctica diplomática de la ciudad de Barcelona entre finales del siglo XV y finales del XVII.

Proponemos una primera definición y descripción del mecanismo y exponemos algunas reflexiones sobre la documentación de los embajadores.

\section{Palabras clave}

Siglos XVI-XVII; Consell de Cent; Barcelona; Diplomacia Urbana; Monarquía Hispánica

\begin{abstract}
Barcelona's legacies to the Spanish Court in Madrid are a well known institutional mechanism during the early modern period, which, however, has not led to a study. This article's objective is to offer the first results of a research about the diplomacy of the city of Barcelona between the 16th and the 17th centuries. It aims at formulating a first definition as well as a description of this institutional mechanism and offers, at the same time, a contribution about the ambassadors' documents.
\end{abstract}

\section{Key Word}

16th-17th Centuries; Consell de Cent; Barcelona; Urban Diplomacy; Spanish Monarchy

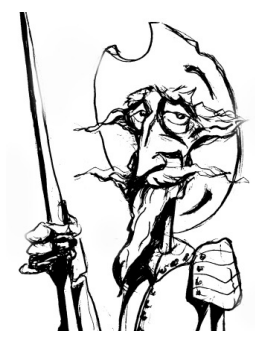

Recibido con pedido de publicación el 3 de febrero de 2021

Aceptado para su publicación el 30 de marzo de 2021

Versión definitiva recibida el 2 de mayo de 2021

Mathias Ledroit, Université Paris-Est Gustave Eiffel Francia, LISAA-EMHIS, París, Francia; e-mail: mathias.ledroit@u-pem.fr

* El autor agradece a los evaluadores de revista Prohistoria por sus comentarios.

Esta obra se publica bajo licencia Creative Commons. Atribución-NoComercial-CompartirIgual 4.0 Internacional

Ledroit, Mathias "Los embajadores del Consell de Cent en la corte de España. Aproximación a la actividad diplomática de la ciudad de Barcelona en la época moderna", Prohistoria, Año XXIV, núm. 35, jun. 2021, pp. 253 - 273 
La diplomatie est vieille

comme le monde

et ne périra qu'avec lui. ${ }^{1}$

Las legaciones de la ciudad de Barcelona a la Corte son un mecanismo conocido para los historiadores de la época moderna. Se trata de una práctica aparentemente consolidada que, sin embargo, no se ha beneficiado de ningún estudio. Solo contamos con las contribuciones, fundamentales, de Manuel Calvo Rodríguez, dedicadas a algunas misiones diplomáticas en concreto en la segunda mitad del siglo XVII (Calvo Rodríguez, 1993). En el presente artículo, se expone una primera aproximación a la práctica diplomática de la Ciudad Condal entre finales del siglo XV y principios del XVIII, es decir, entre la reforma del mecanismo llevada a cabo por Fernando el Católico y su abolición por Felipe V en 1716.

Nos centraremos aquí en tres legaciones en particular. La primera ocurrió entre finales de 1620 y mediados de 1621. Se produjo en un contexto de discordia entre el gobierno real y la ciudad de Barcelona a propósito del quinto real que Felipe III había reclamado (Elliott, 1977: 131-132). La segunda se desarrolló entre 1622 y 1623 y resultó de la polémica iniciada en 1621 en torno al nombramiento del virrey Joan Sentís, sin que Felipe IV hubiera jurado las constituciones (Arrieta Alberdi, 1995: 70-71; Simon i Tarrés, 1999: 121-129). La tercera tuvo lugar en 1632 en un momento de máxima tensión entre la Ciudad y el gobierno real a propósito del privilegio de los Consellers de Barcelona de permanecer cubiertos ante el rey (Elliott, 1977: 244-271; Simon i Tarrés, 1999: 129-136). Sin entrar en el detalle de estas tres legaciones, abordaremos dos aspectos principales: el primero, de índole teórica, nos llevará a formular una primera definición, provisional e incompleta, de las "embajadas" de la Ciudad y a reflexionar sobre el estatus de los "embajadores"; el segundo, más práctico, se centrará en el modo de constitución y de organización de una "embajada", así como en las herramientas de los embajadores, es decir, la documentación que utilizan a lo largo de su misión.

\footnotetext{
${ }^{1}$ René-Alphonse Maulde La Clavière, La Diplomatie au temps de Machiavel, 3 vol., Paris, 18921893, vol. 1, p. 1. "La diplomacia es tan antigua como el mundo y solo perecerá con él". La traducción es nuestra. Este artículo se enmarca dentro del proyecto de I+D+i financiado por el Ministerio de Ciencia e Innovación de España, dirigido por Ida Mauro y Diego Sola García, titulado "Redes de información y fidelidad: los mediadores territoriales en la construcción global de la Monarquía de España (1500-1700) (REDIF)", Universidad de Barcelona, Ref. PID2019-110858GA-I00.
} 


\section{Problema taxonómico y esbozo de definición}

El léxico utilizado en la documentación para designar a los embajadores y embajadas muestra cierta estabilidad en la época moderna. Si bien es cierto que seguimos encontrando palabras como "legacia", "missatger", "legados", "legación", se imponen en la mayoría de los casos los términos "embajada" y "embajador". Estos vocablos, sin embargo, resultan ambiguos y hasta polémicos en la literatura teórica coetánea. De hecho, los diccionarios de lengua clásica definen la palabra "embaxada" como una "comisión, encargo o negocio que lleva el embaxador para el Príncipe a quien es enviado" y la de "embaxador" como el "nuncio o ministro que va en nombre de algún Príncipe a otro, con creencia y carta para tractar negocios, o para asistir en su Corte en su nombre". ${ }^{2}$ De modo que, según los conceptos de la época, un embajador representa a un príncipe soberano, en el marco de las relaciones internacionales, lo que no corresponde a la realidad de la diplomacia barcelonesa. De hecha, esta representa el Consell de Cent, o más bien a los Consellers, la mayoría del tiempo, en el interior del territorio peninsular de la Monarquía, aunque hemos podido documentar unas embajadas enviadas a la curia romana en la época de Felipe II y de Felipe III. ${ }^{3}$ Además, la voz "embajador" coexiste con otra, la de "síndico", que designa a los mensajeros de las ciudades y villas reales, con representación en las Cortes. Los juristas barceloneses del siglo XVII, tendenciosamente, establecen al respecto una diferencia entre Barcelona y las otras ciudades y villas del Principado, considerando que solo los representantes de aquella pueden llevar el título de "embajador", mientras que todos los demás son "síndicos", aunque no sabemos cuándo se impuso esta distinción.

Los escritos teóricos de la época moderna relativos a los embajadores refuerzan esta concepción y reservan la exclusividad del título de "embajador" a los representantes de un poder soberano. Así, por ejemplo, en L'Ambassadeur et ses fonctions, Abraham de Wicquefort aludía en estos términos a las embajadas que el consistorio de la Diputación mandó a Felipe IV en 1640:

“Los diputados que los catalanes enviaron a París en 1640 no eran embajadores ni ministros públicos, aunque llevaban el título. Cataluña se había sublevado, no con la intención de constituirse en soberanía sino a fin de entregarse a otro soberano, de modo que no podía esperar que de su revuelta resultara un cambio de maestro [...]. Ya sé que los catalanes, para justificar su última sublevación, hicieron un gran memorial de varias infracciones de sus privilegios, en el que se

\footnotetext{
2 Diccionario de Autoridades, entradas "embaxada" y "embaxador". Edición en línea, consultada el 11. 6.2019.

${ }^{3}$ Archivo Histórico de la Ciudad de Bacelona [AHCB], Lletres closes, 1B-VI-73, ff. 171v-176v.
} 
quejaban, entre otras cosas, que en Madrid se prohibía dar a los embajadores de Cataluña otro título que el de síndico". ${ }^{4}$

Este comentario acerca de los embajadores de la Generalidad pone de realce que, detrás de la cuestión lexical, se hallaba el problema del título y, por consiguiente, del estatus y de la legitimidad de los embajadores de Barcelona. Para Abraham de Wicquefort, quien escribió a finales del siglo XVII, los mensajeros de Barcelona o del Principado en la Corte no eran embajadores y no podían reclamar ni el título ni el estatus por diversos motivos. Primero, porque el Consell de Cent y la Generalitat ${ }^{5}$ no beneficiaban del derecho de embajada, ya que no eran detentores de la soberanía. Segundo, porque sus mensajeros no eran ministros públicos y no representaban una entidad política soberana o a un príncipe soberano ante otra entidad $u$ otro príncipe soberano y extranjero. Puntualizaba, además, que: “El Embajador es un príncipe público, que un príncipe soberano manda a una potencia extranjera, para representar ante ella su persona en virtud de un poder, de cartas de creencias o de alguna comisión que dé a conocer su carácter". ${ }^{6}$ Asimismo, insistía en el que los súbditos no gozaran del derecho a enviar embajadores a su príncipe sino solo "députés" "diputados"- puesto que "...los diputados, que los súbditos envían a su soberano, solo se dirigen a este con reprimendas y suplicaciones, y no pueden otorgarse a sí mismos el título de ministros públicos ni reclamar la protección del ius gentium". ${ }^{7}$

Semejante razonamiento encontramos en Juan Antonio de Vera, según quien "la embajada propiamente va de príncipe a príncipe, y tal se ha de entender, quien tiene mando absoluto pendiente de su voluntad soberana". ${ }^{8}$

\footnotetext{
4 "Les députés, que les Catalans envoyèrent à Paris en l'an 1640 n'estoient ni Ambassadeurs ni Ministres publics, encore qu'ils en prissent la qualité. La Catalogne s'estoit soulevée, non dans l'intention de s'ériger en souveraineté mais à dessein de se donner à un autre souverain, de sorte qu'elle ne pouvait espérer de sa révolte qu'un changement de maître [...]. Je sçais bien que les Catalans, pour justifier leur dernier soulèvement, firent un grand mémoire de plusieurs infractions de leurs privilèges, où il se plaignoient, entre autres choses, qu'à Madrid on avoit fait défenses de donner aux Ambassadeurs de Catalogne autre qualité que celle de syndic". Abraham de Wicquefort, L'Ambassadeur et ses fonctions, Amsterdam, François L'Honoré et fils, 1746, pp. 19-20.

${ }^{5}$ Como bien a mostrado Víctor Ferro (Ferro, 1996: 137-183), en los textos jurídicos el concepto "Generalitat" se refiere al "reino". En la bibliografía relativa a la historia de Cataluña, sin embargo, el término se utiliza convencionalmente para hablar de la institución de la Diputació del General de Catalunya.

6 “...l'Ambassadeur est un prince public, qu'un souverain envoye à une puissance estrangere, pour y representer sa personne en vertu d'un pouvoir, de lettres de créances, ou de quelque commission qui fasse connoistre son caractère", Abraham de Wicquefort, L'Ambassadeur..., p. 3. 7 “...les députés, que les sujets employent auprès de leur souverain mesme, ne s'adressent à luy que par des remontrances \& par des supplications, ne peuvent se donner la qualité de Ministres Publics ny réclamer la protection du droit des gens", Abraham de Wicquefort, L'Ambassadeur..., p. 18.

8 Juan Antonio de Vera y Zúñiga, El enbaxador por Don Juan Antonio de Vera i Çúñiga, comendador
} 
Juan Antonio de Vera, refiriéndose a las embajadas de la Generalidad de Cataluña, argumentaba de hecho que: "Ni tampoco fue embajada la que el Principado de Cataluña envió a su rey, aunque Zurita le da este título: porque como se ha dicho, y dirá, los vasallos no pueden hacer embajadas, sino diputados". 9

Más tarde, en el siglo XIX, Maulde de Clavière asimilaba derecho de embajada y derecho de guerra, y añadía que:

“...el derecho de embajada, derecho de recibir o enviar agentes diplomáticos pertenece [...] al soberano, al jefe de Estado, al cuerpo que representa y dirige el país en sus relaciones con el extranjero. El derecho de embajada es correlativo del derecho de guerra y ambos no pueden separarse [...]. Un súbdito, un vasallo no puede negociar, puesto que las guerras privadas están prohibidas $\mathrm{y}$, en el extranjero, el primer deber de un vasallo, y más aún de un súbdito, consiste en tener por amigos o por enemigos los de su señor. Así pues, ningún súbdito goza del derecho de embajada". ${ }^{10}$

Maulde de Clavière aseveraba que el siglo XV habría marcado un cambio profundo, una ruptura entre un estado que calificaba de anárquico, en el que vasallos y feudatarios podían sellar pactos entre sí y con extranjeros sin el acuerdo del monarca, a un Estado en el que el rey -Luis XI de Francia en este caso- ejerce el monopolio de la diplomacia, haciendo del derecho de embajada una prerrogativa regia.

En la corte del Rey Católico, el término "embajador", lucido por los mensajeros de Barcelona, suscitó polémicas en repetidas ocasiones. Fue el caso, por ejemplo, en 1623, cuando el embajador, Joan Lluís Vileta, solicitó del Consell de Cent, como prueba fehaciente, una copia autentificada del privilegio que autoriza a la Ciudad a enviar "embajadores". ${ }^{11}$ Un incidente parecido sucedió

de la barra en la orden de Santiago, señor de las villas de Sierra Brava i S. Lorenço, a don Filipe III N.S. glorioso monarca de España enperador de las Indias, Séville, Francisco de Lyra, 1620, f. 35r. Restablecemos el error de la edición de 1620 que indica f. 33.

${ }^{9}$ Juan Antonio de Vera y Zúñiga, El enbaxador..., f. 38r.

10 "...le droit d'ambassade, droit de recevoir et d'envoyer des agents diplomatiques, appartient [...] au souverain, au chef d'État, au corps qui représente et dirige le pays dans ses rapports avec l'étranger. Le droit d'ambassade est corrélatif du droit de guerre et on ne saurait les séparer. [...] Un sujet, un vassal ne peut traiter, puisque les guerres privées sont interdites, et, au dehors, le premier devoir du vassal, à plus forte raison du sujet, est d'avoir pour amis, pour ennemis ceux de son seigneur. Aucun sujet n'a donc droit d'ambassade", René-Alphonse Maulde La Clavière, La Diplomatie..., I, 5, p. 163.

${ }^{11}$ AHCB, Cartes rebudes, 1B-X-86, f. 176r.: "Al senyor Conceller segon havem escrit fos servit manarnos enviar una copia del privilegi te aquexa ciutat de poder nomenar embaxadaor. Suplicam a vm sian servits manarlo enviar ab brevedat, perque assi alguns dificultan en aquest nom de embaxador...". 
en 1632, durante la legación de Francesc Bru. En una de sus entrevistas con el Conde-Duque y el protonotario Jerónimo Villanueva, este lo llamó "síndico", negándole públicamente el título $\mathrm{y}$, por lo tanto, el estatus de embajador. Al regresar Francesc Bru de la Corte, redactó una relación destinada a los Consellers de Barcelona en la que relató detalladamente el incidente y la indignación que manifestó frente a la condescendencia del protonotario:

“...y coneguí tantbé del protonotari lo desgust ne tingué pus me tractà de Síndich. Y la primera volta que era de ell a mi li digui que-m fes mercè de tractar-me com Embaxador pus la siutat tenia aquex Privilegi que no era rehó que ab mi volgués innovar una cosa tant assentada y ell me respongué que·u faria de la manera volria y després en lo quarto del Conde Duque estant jo perlant ab lo marqués de Leganés y essent-hi alguns de nostra nació isqué lo Protonotari y com me veu ab lo marqués li digue, o, aqui esta vostra excel·lència ab lo síndich de Barcelona y responguí-li, Embaxador, senyor, Embaxador y tothom callà perquè Vostre Senyoria sapia y puga manar notar sobre aquesta preheminència per privilegi que $\mathrm{ab}$ mi no ha perdut res lo títol de embaxador antes bé he procurat conservar-lo [...] y quant entrí a besar la mà a sa Magestat y tingui audiència del Compte Duch sempre me cridaven dient entre el embaxador de la Ciutat de Barcelona..."12

En la misma época, los abogados del Consell de Cent consideraban que este privilegio fecharía de finales del siglo XV, más concretamente de 1493. Fernando II de Aragón habría otorgado a la ciudad de Barcelona el privilegio de enviar representantes al rey con título de "embajador" y no de "síndico", como lo leemos en este memorial de 1632 enviado por los Consellers a Francesc Bru: “...y que para sus negocios [acordaron los reyes] pueda [la Ciudad] imbiar a su Magestad embaxadores con este título (y no síndico [...]) como se ve en el privilegio del señor Don Fernando el Católico, concedido a la Ciudad". ${ }^{13}$ Según Joan Pau Xammar, en su Civilis doctrina, el privilegio de Fernando habría sido dado a la Ciudad en Ocaña el 13 de diciembre de 1496. ${ }^{14}$ El privilegio de 1493, reproducido por Jaume Vicens Vives en Ferran II $i$ la Ciutat de Barcelona, en realidad, no alude al sistema de embajadas (Vicens Vives, 1937). En cuanto al de 1496, no lo hemos encontrado. Otros documentos del siglo XVII, como por

\footnotetext{
${ }^{12}$ Antich Dietari de la Ciutat de Barcelone [ADCB], vol. IX, "Relació de l'ambaixada de Francesc Bru a Madrid".

${ }^{13}$ Biblioteca de Catalunya [BC], Memorial con que se responde a otro presentado a los Consellers de la Ciudad de Barcelona, y justifica la pretensión de la Ciudad en lo que toca a la cobertura, Barcelona, Pedro Lacavallería, 1632, p. 37. Fullets Bonsoms 5208.

${ }^{14}$ Joan Pau Xammar, Civilis doctrina de emiquitate et religione, regimine, privilegiis et praehemintentiis inclytae civitatis Barcionae, Barcelona, 1668, cap. VI, núm. 27, p. 37.
} 
ejemplo un pleito formulado en 1623 contra el Conseller en cap Joan Lluís Vileta, mencionan un privilegio dado por Juan I de Aragón en 1390, el cual otorga a la Ciudad la capacidad de transmitir "missatgeries" o "embaxades" "al senyor rey o al Sant Pare o a qualsevol príncep o señor o a alguna ciutat, vila o $1 \operatorname{loc}^{\prime \prime} .{ }^{15}$ Un segundo texto normativo sería el privilegio dado por Fernando II de Aragón en 1498, con el que el Rey Católico procede a una amplia reforma del sistema de insaculación (Vicens Vives, 1937). Se refiere al proceso de extracción de los embajadores y precisa que solo las personas inscritas en las bolsas de insaculación de Conseller en cap, Conseller segon y Conseller ters pueden llevar el título de "embajador". El texto estipula también que los Consellers en cap y segon son elegibles, a no ser que estén impedidos por algún motivo. En cambio, el Conseller ters no puede cumular ambos oficios. Por otra parte, el privilegio precisa que se podrían comisionar hasta tres mensajeros al mismo tiempo y que, en los casos tocantes a mercancías, se podría mandar a un mercader, extraído de la bolsa de los Consellers quarts:

"Item, ordenam que los embaxadors sien trets en presència del Consell de Cent jurats, lo hu de la bossa de Conseller en Cap, en què pugue concórrer en la sor lo Conseller en Cap, e si seran dos, lo segon se hage a traure de la bossa dels Consellers Segons, y si seran tres, se hage a traure lo terç de la bossa de Conseller Terç, però que no hi puguen concórrer en la sort lo Conseller Segon ni Terç, si donchs per mancament o impediment del Conseller en Cap hi hagués concórrer lo Conseller Segon, en lo qual cas pugue concórrer en la sort de la bossa dels Consellers Segon lo Conseller segon. E si era cosa que tocas a mercaderia e paragues al Consell hi degués anar mercader, que en tal cas se pugue traure un mercader de la bossa de Consellers Quarts, pus no sie lo Conseller qui serà quart encara que isqués a la sort. Entès, emperò, que en neguna embaxada no pugue haver més de hun embaxador militar, si per sort serà tret; on no, volem que no sia de necessitat que n·i haja" (Vicens Vives, 1937: 350).

A partir de los elementos mencionados y de los primeros sondeos en el Archivo Histórico de la Ciudad de Barcelona, podemos formular una definición provisional: las embajadas de la ciudad de Barcelona fueron un mecanismo institucional que fue consolidado en la baja Edad Media y reglamentado a finales del siglo XV. Los Consellers mandaban representantes a otras instituciones para recoger e intercambiar informaciones o para proceder a una negociación. Asimismo, los embajadores representaban a los Consellers y al

${ }^{15}$ AHCB, Plets i processos, 05/1B.XXIII-27, f. 115v. 
Consell de Cent fuera de la ciudad, principalmente en la Corte, pero también en la Curia romana o ante el Sumo Pontífice.

\section{Elección y habilitación de los embajadores}

La designación de los embajadores es un proceso institucionalizado y reglamentado. Sabemos que antes de la reforma de 1498, los Consellers establecían una primera lista de nombres y, luego, convocaban una comisión especial integrada por jurados sorteados entre los miembros del Consejo. Procedían a una elección nominativa, cuyo resultado era proclamado por el notario de la Ciudad. Las personas escogidas debían aceptar su misión y prestar juramento de cumplir el mandado de los Consellers. En el caso contrario, los embajadores eran multados, privados de sueldo o imposibilitados en los cargos públicos (Moeglin y Péquignot, 2017: 377). Este proceso fue modificado por el privilegio de 1498. En efecto, en la época moderna, la elección de los embajadores quedó estrechamente vinculada al sistema de las insaculaciones. Después de haber deliberado, en un primer tiempo, enviar una embajada, los Consellers mandan que sean sorteados los nombres de los embajadores de las bolsas de insaculación, como podemos comprobarlo, por ejemplo, en esta deliberación del 5 de septiembre de 1620:

"Lo dit Consell entesa la dita propositió feu delliberació y conclusió que attesa la gravetat del negoci en esta matèria sia feta extractió de tres embaxadors de los bosses de Consellers en cap, segon y tres en la forma acostumada y votats per scrutini per lo present Conseill, los quals sian tramesos a la Cort de sa Magestat pera supplicar sia de son real servey manar sobreseurer en la demanda dels quints feta a la present ciutat..."16

Realizada la extracción, los Consellers votan en secreto mediante un sistema de botones blancos -en contra- y negros -a favor- para habilitar a las personas sorteadas:

“E encontinent en exemple de la dalt dita y primera delliceració per aquest Consell feta de la bossa de Conseller en cap fou extret per embaxador per al Rey señor Micer Francesch Bru, ciutadà y votat per scrutini ab capses y botons blancs y negres com se acostuma y reconeguda aquellas fou trobat tenir tots los botons negres y així fonch habilitat". ${ }^{17}$

El privilegio de 1498 ofrece una serie de informaciones útiles acerca de la composición de las embajadas. En efecto, el texto indica que, en cada misión,

\footnotetext{
${ }^{16}$ AHCB, Registre de deliberacions, 1B.II-129, f. 123r.

${ }^{17} \mathrm{AHCB}$, Registre de deliberacions, 1.B.II-141, f. 270r.
} 
podía haber hasta tres embajadores. Si el Consejo decidía enviar a un único representante, este debía ser sorteado de la lista de Conseller en cap. Si se decidía mandar a dos embajadores, estos debían ser extraídos de las listas de Conseller en cap y Conseller segon. Los Consellers, en cap y segon que ocupaban el cargo podían participar en el sorteo, pero si el Conseller en cap en funciones salía elegido, el Conseller segon no podía ser habilitado. En el caso de las embajadas compuestas por tres representantes, se extraían nombres de las listas de Conseller en cap, Conseller segon y Conseller ters. Al contrario de los otros dos, el Conseller ters en funciones no podía participar en el sorteo.

El privilegio precisaba también que no podía haber más de un miembro del estamento militar entre los embajadores. En las legaciones que hemos podido documentar hasta ahora, la presencia de un noble solo parece ser obligatoria en el caso de las embajadas compuestas de tres embajadores. En 1620-21, por ejemplo, al renunciar Francesc Cornet, de la lista de Conseller segon, el Consejo ordenó un nuevo sorteo. Fue extraído Joan Amat, quien no pudo ser habilitado por ser ciudadano honrado. Lo mismo ocurrió con Joachim Montalt y Pere Font, hasta que fue extraído el nombre de Pau Busquet, quien, por ser donzell, pudo ser habilitado:

“E axí per exequtió de dita delliberació fou proceyt a fer extacció de la bossa de Consellers Segon y fonch tret un rodolí dins lo qual fou trobat sent lo nom del doctor Joan Amat y per ser ciutadà fou extret micer Joachim Montalt, ciutadà y per no poder per ser ciutadà, fou extret lo doctor Pere Font y per ser ciutadà fou extret micer Pau Bosquet, donzell, lo qual votat per scrutini en la forma acostumada fou trobat tenir compliment de vots y axí habilitat per dit Consell". ${ }^{18}$

Si las personas elegidas no estaban presentes en el Consejo, se les notificaba su nominación mediante una carta. Debían acudir al Consell de Cent cuanto antes para ser informados por los Consellers de los motivos de la misión y para recibir las instrucciones. Los embajadores electos no podían rechazar la misión. En caso de impedimento, debían escribir a los Consellers para comunicarles sus motivos. En primera instancia, estos estudiaban los motivos invocados y emitían un primer dictamen. Si la persona designada se mantenía firme en su rechazo, debía entrevistarse personalmente con el Conseller en cap, quien formulaba un segundo y último dictamen. Si este consideraba válidos los motivos invocados, se procedía a una nueva extracción, como lo evidencia la siguiente deliberación:

"E mes fonch proposat los magnifichs micer Jaume Aymerich y Micer Francesch Cornet embaxadors extrets en lo Consell decent a sinch del corrent y habilitats per dit consell pera anar a

18 AHCB, Registre de deliberacions, 1B.II-129, f. 125. 
la cort de sa Magestat a suplicar lo sia de son real servey manas sobreseurer en lo manteniment y demanda dels quints de les imposicions de la ciutat hauria suplicat als señors consellers que el admetessen la renuntiatio perque ells per sos justs impediments axi de sa [...] com altrament estavan imposibilitats de poder servir a la Ciutat y aix renuntiant dit carrech de embaxadors empero dits magnifichs Consellers no havian admesas ditas renuntiations per ço que tocava al present Consell admetrerlas o dexarles de admetre y axi ho presentaven al dit present consell pera que dellibere sils seran admesas ditas renunciacions o no.

E lo dit Consell per justes causes y rahons que en asso ha considerades ha deliberat que no sels sia admesa la renunciatio sino que lo present consell los mane en la manera que sols hils pot manar accepten lo carrech de dita embaxada y que dits embaxadors teornen resposta si volen acceptar o no abans de disgregarse lo present consell.

Per exequtio de la qual delliberacio foren cridats los dits micer Jaume Aymerich y Micer Francesch Cornet als quals fou y en lo magnifich Conseller en cap referida la dita delliberatio a la qual sentintse lo dit magnifich micer Jaume Aymerich per justissimes rahons y causes al servey de la ciutat respongue que acceptave lo dit carrech de embaxador empero lo dit micer Francesc Cornet perseverant en lo sobredit supplica de nou que per les causes sobre ditas li sia admesa dita renunciatio". ${ }^{19}$

Estas primeras informaciones nos permiten esbozar un perfil de los embajadores, dado que solo podían ser habilitados los que estaban inscritos en las listas de insaculación. Víctor Ferro mostró que para ser insaculado se exigían algunas condiciones, por lo menos hasta 1652 (Ferro, 1996: 164-166), cuando Felipe IV modificó las modalidades de constitución de estas listas después de la reintegración de Cataluña tras la revuelta de 1640. Para ser insaculado, pues, era necesario ser catalán o hijo de catalán, haber cumplido los 25 años y tener residencia en la ciudad de Barcelona. Para las personas que no habían nacido en Barcelona, era preciso haber residido en la ciudad o en la veguería durante más de diez años. Era necesario ser cristiano viejo, no haber cometido ningún crimen o delito y no ocupar un cargo en la administración real. Víctor Ferro nos indica también que había ciertos requisitos de edad en algunos casos (Ferro, 1996: 164166). Así, por ejemplo, era necesario haber cumplido los 40 años para ser elegido Conseller en cap, los 35 años en el caso de un Conseller segon y los 30 para los Consellers ters.

${ }_{19}$ AHCB, Registre de deliberacions, 1B.II-129, f. 124r. 
Antes de emprender el viaje a la Corte, los embajadores debían prestar juramento ante el Consejo. El texto, en latín, estipulaba que los embajadores debían defender los intereses de la Ciudad y seguir las instrucciones de los Consellers. En ningún caso debían desprestigiar la Ciudad o aprovecharse de su misión para beneficios privados. Recibían una suma de dinero, 400 lliures catalanes repartidas del siguiente modo: 200 para la indumentaria y otras 200 de salario para el primer mes. ${ }^{20}$ Recibían un conjunto de documentos: las instrucciones, las cartas de creencia, las cartas de recomendación, una serie de memoriales redactados por los abogados de la ciudad y las copias autentificadas de "actas", es decir de documentos oficiales -privilegios, constituciones, etc.- que podrían serles útiles en el marco de sus negociaciones con el rey, con los ministros o con los regentes del Consejo de Aragón.

\section{Herramientas de la diplomacia barcelonesa}

Los documentos que reciben los embajadores antes de su partida merecen un examen detallado. En esta sección, nos centraremos en las cartas de creencia, las instrucciones y la correspondencia. Estos documentos son esenciales en la práctica diplomática, tanto si hablamos de la diplomacia de los príncipes como de la actividad diplomática de las ciudades. Por una parte, son ellos principalmente la creencia y las instrucciones- los que acreditan al embajador en la Corte (Fedele, 2017: 233-234). Dicho de otra manera, son las instrucciones y, más aún, las cartas de creencias, las que elevan el mensajero a la categoría de embajador.

\section{Las cartas de creencia}

Las cartas de creencia son documentos emitidos por los mandantes para acreditar a sus mensajeros. Sabemos que estas cartas no son exclusivas de la práctica diplomática, ya que también se utilizan en el ámbito del negocio (Péguignot, 2009: 32-34). Sin embargo, son un elemento constitutivo y decisivo de la práctica diplomática (Lazzarini, 2015; Fedele, 2017: 234-239). Se pueden identificar a partir de cuatro elementos: el destinatario, la notificación, la supplicatio -es decir el objeto de la misión-, la fecha y la firma del remitente (Fedele, 2017: 234-239). En el caso de las cartas entregadas a los embajadores de Barcelona notamos, primero, que son producidas en serie, excepto la carta dirigida al monarca. Las otras son idénticas y solo cambia el nombre del destinatario. La carta dirigida a Felipe III en 1620 presenta todas las características de una creencia. Es dirigida nominativamente al monarca, notifica la embajada, expone una suplicación detallada y menciona la fecha. El texto recuerda que el Consell de Cent, conforme a los privilegios de la Ciudad,

${ }^{20} \mathrm{AHCB}$, Registre de deliberacions, 1B.II-129, f. 124r. 
manda una embajada al monarca para tratar un asunto grave e importante. La carta menciona el nombre de los tres embajadores y pide al rey que les conceda audiencia, fe y creencia:

"[El asunto] necessita molt de que Vostra Magestat estiga ben interat de esta veritat y no és possible ab cartes ha deliberat lo Savi Consell de Cent trametre a Vostre Magestat per este esta embaixada a Micer Jaume Aymerich, doctor en dret y ciutadà honrat de esta ciudad, Micer Pau Boquet, doctor en dret, donzell y Micer Antoni Vinyola, doctor en dret y també ciutadà honrat segons lo tenor dels privilegis de esta ciutat suplican a Vostra Magestat de part de esta ciutat quant humilment poder sia de son real servey donarlos grata audiència y entera fe y crehensa en lo que per part de esta ciutat explicaran..."21

\section{Las instrucciones}

Las instrucciones son, también, una constante. Para cada embajada enviada a la Corte, una junta de dieciséis personas, cuatro por cada estamento, elabora una serie de instrucciones, ${ }^{22}$ cuya extensión puede variar según el motivo y la complejidad de la misión. Desde un punto de vista formal, las instrucciones del siglo XVII presentan una cierta homogeneidad. Se presentan bajo la forma de una lista de puntos más o menos larga y detallada. No llevan ninguna fecha, pero podemos datarlas a partir del registro de deliberaciones del Consejo o gracias al encabezado que aparece en los registros de correspondencia. Son documentos prescriptivos y se presentan bajo la forma de un guión que contempla la misión en su conjunto, desde la salida de Barcelona hasta el regreso. Detallan las principales obligaciones de los embajadores, así como los argumentos que tendrán que utilizar para negociar con los regentes del Consejo de Aragón, con los ministros o con el rey. Son, por así decir, una trama que los embajadores deberán seguir concienzudamente, lo cual les deja un margen de libertad bastante limitado (Péquignot, 2008; Fedele, 2017: 239-242).

Las instrucciones de 1620-1621 son un documento ejemplar por su carácter detallado, lo que no es el caso de todas las instrucciones que hemos localizado hasta ahora. ${ }^{23}$ Notamos que el texto se caracteriza por su progresión. Los tres primeros párrafos explican detalladamente el contenido de la embajada y sus motivaciones: las informaciones que los embajadores deben comunicar al rey, lo que deben solicitar de él y, por consiguiente, lo que deben conseguir, en este caso, la exención del quinto real. En estos tres primeros párrafos, todo ocurre como si nada pudiera impedir la negociación, descartando cualquier tipo

\footnotetext{
${ }^{21}$ AHCB, Registre de deliberacions, 1B.II-129, f. 123r.

${ }^{22} \mathrm{AHCB}$, Registre de deliberacions, 1B.II-129, f. $123 \mathrm{r}$.

${ }^{23}$ AHCB, Lletres closes, 1B.VI-79, f. 15v.-22r.
} 
de oposición o dificultad. Constituyen, por lo tanto, un primer guión: los embajadores se contentan con comunicar al monarca lo anticonstitucional de la petición del quinto real, apoyándose en los memoriales elaborados por los abogados de la ciudad. Las instrucciones precisan que, en caso de no encontrar dificultad alguna, los embajadores disponen de un cierto grado de autonomía, ya que pueden escoger libremente entre los diversos argumentos contenidos en los memoriales: “...se'n aportaran un memorial en dret firmat dels magnifichs advocats de la ciutat y doctors aplicats de la qual pendran lo que-ls aparexerà convenient a son propòsit". ${ }^{24}$ También, si lo consideran conveniente, podrán enseñar al rey las copias autentificadas de los privilegios de la ciudad y, en este caso concreto, el privilegio concedido por Alfonso III en $1286 .{ }^{25}$

Las instrucciones contemplan, sin embargo, la posibilidad que este primer guión sea insuficiente y que la negociación resulte más complicada. De hecho, los párrafos siguientes muestran que las personas encargadas de elaborar estas instrucciones intentan anticipar las réplicas del rey, de los ministros o de los regentes del Consejo de Aragón. Se idean respuestas argumentadas y cada argumento o contraargumento viene reforzado por un documento justificativo, la mayoría del tiempo la copia de un privilegio o de una carta patenta. En última instancia, los embajadores deben relatar una serie de actos positivos, es decir una serie de circunstancias en las que los reyes de Aragón o los reyes de España dispensaron públicamente a la Ciudad de pagar el quinto, remitiendo así a la memoria oficial de la urbe, recogida en las crónicas o en los anales. Finalmente, en el caso que no bastaran los argumentos, los embajadores deben entregar al rey un "memorial de gastos" que recapitulara todas las sumas de dinero otorgadas por la ciudad a los reyes de Aragón y a los de España, así como todas las sumas que fueron imputadas al presupuesto de la ciudad cuando debían ser pagadas por las arcas reales:

“Y peraque dits embaxadors pugan respresentar a sa Magestat y a las personas a qui serà servit commettre dit negoci, los mèrits que concorren a la ciutat acerca del empleo de ditas imposicions ultra dels avantdits serveys de que se ha fet menció en lo precdent capítol per los quals se deu fer mercè a dita ciutat de que nos passe avant en la pretentió dels quints se n'aportaran un memorial de gastos ha fets la ciutat de Barcelona emplant las imposicions en cosas que havian de pagarse del patrimoni del rey nostre señor que són de summa per tots los dits vuit anys de més de [...] lliures y axí molt més del que lo senyor rey podria tenir en ditas imposicions". ${ }^{26}$

\footnotetext{
${ }^{24}$ AHCB, Lletres closes, 1B.VI-79, f. 15v.-22r.

${ }^{25}$ AHCB, Lletres closes, 1B.VI-79, f. 15v.-22r.

${ }^{26}$ AHCB, Lletres closes, 1B.VI-79, f. 15v.-22r.
} 
De no funcionar esta estrategia, los embajadores deberían presentar otro memorial con un inventario preciso y detallado de las sumas de dinero que la Corona debe reembolsar a la Ciudad. Una vez utilizadas todas estas estrategias, los embajadores reciben, mediante carta del Consejo, una orden de regreso, independientemente, en teoría, del éxito o del fracaso de la misión.

Así que, a priori, las instrucciones funcionan como una sucesión progresiva de tramas o guiones que idean el desarrollo de la negociación y las dificultades con las que podrían encontrarse los embajadores. Estos documentos encierran, con más o menos precisión según los casos, los propósitos y las palabras que deben usar los embajadores al entrevistarse con el rey o con los ministros. En esta serie de guiones, el primero no toma en cuenta ninguna dificultad o ninguna oposición y autoriza a los embajadores un cierto grado sino de libertad, por lo menos de autonomía, la cual se reduce conforme va complicándose la misión, hasta llegar a un grado nulo. En definitiva, cuanto más difícil y compleja resulta la negociación, menos libertad tienen los embajadores.

\section{La correspondencia}

La correspondencia entre los Consellers y sus embajadores constituye la parte más importante y voluminosa del corpus documental. Conservamos de hecho la casi totalidad de las cartas intercambiadas a lo largo de cada legación. Todas las cartas -o más bien copias- son fechadas y registradas cronológicamente. Los embajadores y sus mandantes se cartean por lo menos una vez a la semana. El correo llega a la Corte o a Barcelona gracias a la estafeta, ${ }^{27}$ pero también puede llegar por correo de la ciudad, ${ }^{28}$ una suerte de envío especial.

El estudio de la correspondencia permite reconstruir la legación, el avance de las negociaciones, las dificultades con las que se enfrentan los embajadores en la Corte y, a veces, las discrepancias entre los embajadores y sus mandantes. En su carta semanal, los embajadores informan a los Consellers sobre cuanto han hecho, sobre las personas con las que se han entrevistado, sus dificultades para conseguir una entrevista con el monarca, etc. Comunican las fechas de audiencias y piden precisiones o instrucciones complementarias, cuando la misión no se desarrolla como lo preveían las instrucciones iniciales.

La correspondencia también sirve para solicitar copias certificadas de los documentos necesarios para la negociación: copias de deliberaciones del Consejo, de privilegios, de cartas reales o de constituciones, por ejemplo. Si la misión dura más, también solicitan más dinero a los Consellers, quienes les

\footnotetext{
${ }^{27}$ AHCB, Lletres closes, 1B.VI-79, f. 34v.

${ }_{28}$ AHCB, Lletres closes, 1B.VI-79, f. 169v: "Per Benet Mercer correu de la present ciutat trametem a vostre merçè lo present plech...".
} 
envían bajo forma de carta de cambio, seguramente para evitar los robos en el camino. Los embajadores también piden a sus mandantes cartas de agradecimiento para las personas con las que se han entrevistado durante su estancia en la Corte.

Más generalmente, la correspondencia presenta un interés doble. Además de informarnos sobre el contenido de las legaciones, también nos proporcionan detalles sobre la práctica de la diplomacia urbana.

\section{Embajadores en la Villa y Corte}

Las condiciones de viaje y de estancia en la Villa y Corte son, de por sí, un tema de estudio que merecerá una atención especial. En las líneas que siguen, no pretendemos ser exhaustivos, sino más bien presentar unas pistas de reflexiones, a partir de correspondencia generada por las tres legaciones ya mencionadas.

Al llegar a la Corte, los embajadores deben solicitar una audiencia al rey. Para conseguirla, necesitan una carta de recomendación de parte del Consejo de Aragón, y más concretamente de parte del vice-canciller, "pera ocupar lloc de besar les mans de sa Magestat y explica[r]-li [la] embaxada". El vice-canciller del Consejo de Aragón entrega esta carta al responsable del protocolo, quien se encarga de inscribir a los embajadores en una lista de personas a las que se concede una audiencia real. Los embajadores pueden tardar hasta varias semanas antes de conseguir "hora e lloch", es decir una entrevista con el monarca. Durante la demora, los embajadores visitan a personas influyentes en la Corte y les entregan las cartas de recomendación. Estas entrevistas, sin embargo, son simples visitas de "compliment y cortesia" y no sirven para abordar el contenido de la embajada, sino más bien para atraerse la simpatía y el respaldo de ciertos cortesanos:

"Als 6 del corrent avem rebuda per correu propi de vostres magn de 30 del passat y juntament ab ella les instruccions, memorials en dret y altres papers conferents a nostra embaxada fins vuy anem ocupant lo temps en visitar los señors vicecancellir y demes del Consell Supremo de Aragó [...] lo matex continuàvem $a b$ les demés persones para que tenim cartes y com estes primeres visites són de compliment y cortesia, no avem parlat cosa de consideració tocant al negoci y també per no aver explicat encara nostra embaxada a sa Magestat..." 29

${ }^{29}$ AHCB, Cartes Rebudes, 1.B.X.65, carta del 10 de octubre de 1620. 
La correspondencia revela que las negociaciones no son gratuitas y que los embajadores suelen dar estrenas a las personas con las que se entrevistan. Esta práctica parece ser habitual, como lo sugiere la expresión "per donar les estrenes acostumades". ${ }^{30}$ Los embajadores pueden recibir la visita y el respaldo de ciertas personas influyentes. En 1620, los embajadores reciben públicamente el apoyo de Pau Xerquies, "una de les personas que asi nos ha acompanyats mostrant-se públicament interessat en los negocis de aquexa ciutat, com a natural d'ella". ${ }^{31}$ El texto de esta carta del 24 de octubre de 1620 indica que no era la primera vez que Pau Xerquies manifestaba públicamente su apoyo a los embajadores barceloneses. De ahí, la pregunta de saber si, en la práctica, el éxito de la misión depende, primero, de la capacidad de los embajadores a atraerse el apoyo de los personajes influyentes en la Corte y, por otra parte, de la posible existencia en la misma de redes pro-catalanas y/o pro-barcelonesas.

Cuando, por fin, los embajadores acceden al monarca, siempre van acompañados de "alguns señors catalans que ens avien feta mercè per lo camí". ${ }^{32}$ Los embajadores besan las manos (o la mano) del monarca, le exponen el motivo de su embajada, le entregan la carta de creencia y un memorial en derecho. Todo indica, a lo menos en la legación de 1620-1621, que el encuentro con el rey es muy breve y que solo sirve para abrir las negociaciones que, posteriormente, se llevan a cabo entre los embajadores y los ministros del rey o los regentes del Consejo de Aragón.

\section{De vuelta a Barcelona}

Al volver de su misión, los embajadores deben presentarse ante el Consejo para hacer un informe detallado. El relato es generalmente consignado y la relación resultante del mismo, insertada entre los folios del registro de deliberación. En algunos casos, sin embargo, las relaciones se hacen oralmente ante los Consellers y el escribano transcribe el contenido del relato en el registro de deliberación.

Las relaciones son relatos bastante largos y detallado que siguen un modelo preciso. Empiezan con un recordatorio de la orden dada a los embajadores de ir a la Corte. Mencionan el día de la salida de Barcelona y el de la llegada a Madrid. Relatan las circunstancias del viaje y consignan los dichos y hechos de los embajadores en la Corte: las personas con quienes se han entrevistado, el avance de las negociaciones, las dificultades con las que se han enfrentado y cómo las han solucionado. Independientemente del resultado de la misión, las relaciones sirven para poner de manifiesto que los embajadores no han fallado y han seguido concienzudamente las instrucciones del Consejo, es decir que han respetado el mandato.

\footnotetext{
${ }^{30}$ AHCB, Cartes Rebudes, 1.B.X.65, carta del 10 de octubre de 1620.

${ }^{31}$ AHCB, Cartes Rebudes, 1.B.X.65, carta del 24 de octubre de 1620.

${ }_{32}$ AHCB, Cartes rebudes, 1B.X.65, carta del 17 de octubre de 1620.
} 
Además de los argumentos jurídicos, del resumen de las negociaciones y del inventario de las personas con quienes han intercambiado en la Corte, predomina el léxico de las emociones, particularmente el del amor del rey para su ciudad y el de la honra de la ciudad. La constante evocación de las emociones y de la honra, que han defendido los embajadores a lo largo de su misión, sugieren que uno de los papeles fundamentales de las embajadas consiste en desarticular las tensiones y practicar una política que estribaría en una negociación constante y en el compromiso, además de paliar la rarefacción de las Cortes. Parece que este mecanismo tiene como principal objetivo el de revitalizar, mediante la presencia de embajadores en la Corte, el vínculo entre Barcelona y el rey. De hecho, cabe recordar que Barcelona pertenece al dominio real y que al dirigirse al monarca se dirige tanto al Rey Católico como a su señor natural.

\section{Conclusión}

Los estudios acerca de este tipo de legaciones, en una monarquía compuesta o policéntrica, y además en una entidad política como la Corona de Aragón, resultan interesantes y útiles por diversos motivos. La historiografía de la Corona de Aragón, y más aún la catalana, se han dedicado al pactismo como ideología y como herramienta del ejercicio del poder. Difícilmente se puede negar la realidad del pactismo. Sin embargo, ¿cómo se ejerce el pactismo en la práctica? Los estudios realizados al respecto se basan, muy a menudo, en discursos políticos o memoriales elaborados por los abogados de las instituciones, el Consell de Cent y la Generalitat. Dicho de otra manera, ofrecen una aproximación teórica al tema: las relaciones entre las instituciones catalanas y el gobierno de la Monarquía son pensadas y descritas a partir de documentos conceptuales y teóricos. En cambio, el estudio de las legaciones podría ser una puerta de entrada hacia la praxis, para escribir una historia más integrada de la ciudad de Barcelona en la Monarquía católica, a partir de sus singularidades y poniendo de realce el pragmatismo y la práctica de su administración y de su relación con la Corona. Si bien es cierto que el "pactismo" es considerado el principal modo de gobierno en la época moderna, no podemos negar que un "pacto" implica una "negociación" entre los diversos actores del poder, y en el caso que nos interesa, entre el Consell de Cent y el gobierno de la monarquía. 


\section{Bibliografía citada}

Andretta, Stefano - Péquignot, Stéphane - Waquet, Jean-Claude (éds.) (2015). De l'ambassadeur. Les écrits sur l'ambassadeur et l'art de négocier de la fin du Moyen Âge au début du XIXe siècle, Rome: École Française de Rome.

Arrieta Albedi, Jon (1995). "La disputa en torno a la jurisdicción real en Cataluña (1585-1640): de la acumulación de la tensión a la explosión bélica", Pedralbes, núm. 15, pp. 33-93.

Calvo Rodríguez, Manuel (1999). “Embajadas y embajadores de Barcelona enviados a la corte en la segunda mitad del siglo XVII", Pedralbes, núm. 13-I, pp. 535-544.

Calvo Rodríguez, Manuel (1998). “L'ambaixada catalana de Francesc Puigjaner a París: de julio de 1646 a març de 1647", Pedralbes, núm. 18-II, pp. 81-88.

Elliott, John H. (1977). La rebelión de los catalanes. 1598-1640, Madrid: Siglo XXI.

Fedele, Dante (2018). “Uno scritto sull'ambasciatore del secondo Cinquecento. Il Messagiero di Torquato Tasso", Il pensiero politico, anno LI, núm. 1 (gennaioaprile), pp. 113-125.

Ferro, Víctor (1996). El dret públic catalá. Les institucions de Catalunya fins al Decret de Nova Planta, Vic: Eumo.

Gilli, Patrick (2009). "La fonction d'ambassadeur dans les traités juridiques italiens du XV siècle : l'impossible représentation", Mélanges de l'École Française de Rome. Moyen Âge, t. 121, núm. 1, pp. 173-187.

Gilli, Patrick (2015). “Bernard De Rosier et les débuts de la réflexion théorique sur les missions d'ambassade", en Andretta, Stefano, et al. De l'ambassadeur : Les écrits relatifs à l'ambassadeur et à l'art de négocier du Moyen Âge au début du XIX siècle. Rome: Publications de l'École française de Rome, pp. 187-199.

Gilli, Patrick (2015). “Ambassades et ambassadeurs dans la législation statutaire italienne (XIII-XIV siècle)", en Andretta, Stefano, et al.. De l'ambassadeur: Les écrits relatifs à l'ambassadeur et à l'art de négocier du Moyen Âge au début du XIX siècle. Rome: Publications de l'École française de Rome, pp. 57-87.

Krischer, André (2010). "Syndici als Diplomaten in der Frühen Neuzeit. Repräsentation, politischer Zeichergrebrauch und Professionalisierung in der reichsstädteischen Außenpolitik", en Jörg, Christian et Jucker, Michael Spezialisierung und Professionalisierung. Träger und Foren städtischer Außenpolitik während des späten Mittelalters und der frühen Neuzeit, Wiesebaden: Reichert, pp. 254-286.

Lazzarini, Isabella (2015). Communication and Conflict. Italian Diplomacy in the Early Renaissance (1350-1520), Oxford: Oxford University Press. 
Moeglin, Jean-Marie et Péquignot, Stéphane (dirs.) (2017). Diplomatie et "relations internationales" au Moyen Âge (IX ${ }^{e}-X V^{e}$ siècle), Paris: Presses Universitaires de France.

Péquignot, Stéphane (2008). "Les instructions aux ambassadeurs des rois d'Aragon (XIII-XVe siècles). Jalons pour l'histoire de la fabrique d'une parole royale efficace", Cahiers d'Études Hispaniques Médiévales, núm. 31, pp. 17-43.

Péquignot, Stéphane (2009). Au nom du roi. Pratique diplomatique et pouvoir durant le règne de Jacques II d'Aragon (1291-1327), Madrid: Casa de Velázquez.

Senatore, Francesco (1998). "Uno mondo de carta". Forme e strutture della diplomazia sforzesca, Naples: Liguori.

Simon i Tarrés, Antoni (1999). Els orígens ideològics de la revolució catalana de 1640, Barcelona, Publicacions de l'Abadia de Montserrat.

Vicens Vives, Jaume (1937). Ferran II i la Ciutat de Barcelona, t. 3, p. 350. 